\title{
Sistema Personalizado de Ensino, Educação à Distância e Aprendizagem Centrada no Aluno ${ }^{1}$
}

\author{
João Claudio Todorov \\ Instituto de Educação Superior de Brasília \\ Márcio Borges Moreira ${ }^{2}$ \\ Instituto de Educação Superior de Brasília \\ Universidade de Brasília \\ Ricardo Corrêa Martone \\ Núcleo Paradigma
}

\begin{abstract}
RESUMO - O Sistema Personalizado de Ensino (PSI), amplamente utilizado nos anos 1970, e a Educação à Distância (EAD) são duas metodologias de ensino que rompem com modelos tradicionais de educação, nos quais o centro crítico de transmissão de informação é o professor. O presente trabalho apresenta as principais características dessas duas formas de ensinar, ressaltando suas similaridades. Alguns estudos nos quais PSI e EAD foram utilizados em conjunto são descritos e as vantagens de tal junção são discutidas. Sugere-se, ao final deste trabalho, que o uso conjunto do PSI e da EAD pode ser uma forma viável de disseminação e democratização de um ensino de qualidade, alicerçado em evidências empíricas de sua eficácia.
\end{abstract}

Palavras-chave: educação; sistema personalizado de ensino; educação à distância.

\section{Personalized System of Instruction, Distance Learning, and Student-Centered Learning}

\begin{abstract}
Personalized System of Instruction (PSI), broadly employed in the 1970's, and Distance Learning (DL) are teaching methodologies that differ from the traditional models of education, in which the critical core of information transmission is the teacher. This work presents the main features of both PSI and DL, highlighting their similarities. Studies in which PSI and DL were used together are described, and the advantages of this junction are discussed. It is suggested, at the end of this work, that using PSI and DL together may be a viable way of dissemination and democratization of quality education, based on empirical evidence of its effectiveness.
\end{abstract}

Keywords: education; personalized system of instruction; distance learning.

Uma das marcas fundamentais do processo educacional é a necessidade de um planejamento constante. Planejar práticas educacionais mais eficientes não significa somente escolher um material adequado para o curso que será ministrado, conhecer minimamente as características das pessoas que participarão do processo de aprendizagem, pesquisar e utilizar métodos efetivos de ensino que de fato propiciem condições para o aprendizado etc. Planejar significa também ter total clareza dos objetivos que se quer alcançar, ou seja, saber especificar claramente os comportamentos que gostaríamos de observar em nossos alunos ao final do processo, assim como fornecer as condições mais apropriadas para que esses comportamentos sejam de fato adquiridos.

Descreveremos neste artigo o Personalized System of Instruction (PSI; traduzido para o português como Sistema Personalizado de Ensino), uma metodologia de ensino idealizada pelos professores Fred Keller, Carolina Martuscelli Bori, John Gilmour Sherman e Rodolpho

1 Versões preliminares deste trabalho foram apresentadas pelo primeiro e segundo autores no XV Encontro Brasileiro de Psicoterapia e Medicina Comportamental, realizado em Brasília, 2006. Os autores agradecem ao Dr. Cristiano Coelho pela cuidadosa revisão feita neste trabalho.

2 Endereço para correspondência: QMSW 05, Lt. 2, Bl. D, Apto. 105. Brasília, DF. CEP 70500-680. Fone: (61) 8154-8063. E-mail: borgesmoreira@gmail.com.
Azzi em 1963, e embasada em princípios fundamentais da Análise do Comportamento (Keller, 1968). Implantado na Universidade de Brasília em 1964, foi amplamente utilizado, principalmente nos anos 70. Em 1979 havia cerca de 5.000 cursos conhecidos baseados no PSI, um periódico específico para o assunto (Journal of Personalized Instruction) e, de 1973 a 1979, manteve-se em funcionamento o Center for Personalized Instruction na Georgetown University (Fox, 2004).

A flexibilidade do método é uma de suas mais atraentes qualidades, pois possibilita o uso de uma diversidade de recursos educacionais, tradicionais ou não, para compor um curso no formato do PSI. O papel do professor no PSI diferencia-se de seu papel no ensino tradicional. A função principal deixa de ser a de transmitir conhecimento e passa a ser a de acompanhar, aprimorar, treinar e gerenciar (Todorov \& Tristão, 1975).

Educação à Distância (EAD), a exemplo do PSI, também é uma forma de se ensinar que rompe com os modelos educacionais tradicionais, nos quais o centro crítico de transmissão de informação é o professor. Tanto no PSI quanto na EAD, $\mathrm{o}$ ator principal é o aluno, o aprendiz. Em virtude disso, este trabalho estabelece paralelos entre PSI e EAD, ressaltando suas características comuns e as possibilidades de interação entre essas duas tecnologias de ensino. 


\section{Uma Breve Reflexão sobre Ciência e Educação}

A prática de reunir crianças, adolescentes e jovens adultos ao redor de um mestre, conhecedor dos segredos do mundo e das práticas mais apropriadas para ensiná-los, remonta às civilizações mais antigas da história humana. $\mathrm{O}$ ensino na antiga Roma, por exemplo, principalmente após as propostas reformadoras do educador Quintiliano, já apresentava muitas das características que ainda hoje podemos encontrar em nossas práticas educacionais: a criança deve começar a frequentar a escola o mais cedo possível; deve-se identificar grandes talentos entre os alunos; o tratamento deve ser diferenciado de acordo com as características individuais; os alunos devem ser distribuídos por classes; deve-se aproveitar a memória do aluno como peça chave no processo educativo; a educação deve contribuir para o desenvolvimento das disposições "naturais"; não se deve abusar do uso da varinha ou da palmatória, por considerar que a correção física é não só degradante como também ineficaz; deve-se utilizar a emulação e sobretudo o bom exemplo como incentivos para o estudo; o tempo reservado ao estudo deve ser periodicamente interrompido por recreios, já que o descanso é favorável à aprendizagem; deve-se instruir os alunos simultaneamente em diversas disciplinas (cf., Marrou, 1966).

Passados quase 2.000 anos, as modificações educacionais propostas por Quintiliano, ou pelo menos grande parte delas, ainda estão na ordem do dia quando o assunto é ensinar pessoas. Não é objetivo deste trabalho discutir o surgimento de práticas mais ou menos efetivas ao longo da história, nem temos a pretensão de macular a herança cultural grecoromana. As reformas realizadas por Quintiliano apontadas aqui servem mais como uma ilustração do patamar em que nos encontramos quando falamos de práticas educacionais - continuamos a repetir padrões educacionais que foram inovadores em outras épocas, mas que nos dias de hoje parecem estar resultando em baixa produtividade.

Não acreditamos mais, por exemplo, que a Terra equilibra-se sobre criaturas demoníacas e gigantescas, nem supomos mais que os raios de uma tempestade ocorrem por vontade divina. Entretanto, ainda acreditamos que o comportamento humano é o resultado de forças internas intangíveis, como vontades, desejos, motivações e inteligência, e, por isso, inatingíveis. Assim, facilmente chama-se de "desmotivado" o aluno que não tira boas notas ou que vem frequentando pouco a sala de aula, julga-se "menos inteligente" o aluno que não acompanha o ritmo dos colegas e apresenta continuamente dificuldades de entendimento da matéria. Culpabilizar o aluno foi e continua sendo uma prática corriqueira em instituições de ensino.

Um estudo científico do comportamento humano parece ser uma alternativa promissora para o planejamento de práticas educacionais mais efetivas que possam promover a sobrevivência de nossa cultura (Skinner, 1953). Essa proposta de Skinner parece finalmente estar ocupando lugar dentro da educação. Por exemplo, em 08 de Janeiro de 2002, o então presidente dos Estados Unidos da América, George W. Bush, assinou a Lei No Child Left Behind (Nenhuma Criança Deixada Para Trás), que estabelece que as práticas pedagógicas utilizadas nos Estados Unidos devem demonstrar efeitos mensuráveis no aprendizado das crianças norte-americanas. A Lei enfatiza ainda que a adequação e efetividade dos programas educacionais devem ser avaliadas com base em evidências empíricas, cunhadas sob o rigor dos métodos da experimentação científica (Moran, 2004).

A aprendizagem é um fenômeno que ocorre a todo instante, pois o comportamento expresso pelas pessoas é o resultado de suas relações estabelecidas com o ambiente (sobretudo quando outras pessoas são o ambiente). Entretanto, dispor contingências (i.e., interações ente o indivíduo e seu ambiente, sobretudo o ambiente social) educacionais significa mais que isso, significa estabelecer condições para o surgimento do comportamento desejado e estabelecer consequências que possam fazer com que esse comportamento possa reaparecer novamente em condições semelhantes. Isso quer dizer que o processo educacional deve consistir em arranjar contingências de reforçamento sob as quais o comportamento possa mudar (Skinner, 1968). A expressão "arranjar contingências" revela o caráter planejado do ensino, pois o ensino formal e minuciosamente planejado permite agilizar e otimizar as mudanças comportamentais almejadas.

\section{Conhecer também é um Comportamento}

Conhecer é comportar-se de forma produtiva. Isso fica evidente no simples fato de submeter estudantes a testes teóricos e práticos. Raramente aprova-se um aluno que diz: "Eu sei isso, só não sei escrever/dizer/fazer". Sabemos o que os outros sabem vendo-os se comportar e produzir desempenhos adequados: isto é, vendo-os executar uma tarefa, elaborar uma redação ou relatório, proferir uma palestra, resolver um problema de ordem prática ou teórica, responder questões de um questionário ou teste etc.

E comum a divisão do conhecimento em dois tipos (Baum, 1994/1999; Catania, 1989/1999; Ryle, 1949): saber como (ou saber operacional) e saber sobre (ou saber que; saber declarativo). Saber sobre refere-se ao comportamento verbal (e.g., explicar adequadamente como se dirige um automóvel). Saber como refere-se ao comportamento operante não-verbal que produz consequências adequadas (e.g., dirigir um automóvel sem "barbeiragens").

Entender assim o conhecimento coloca o professor, sobretudo aquele que ensina como ensinar (professores de pedagogia, psicologia, magistério etc.), em uma situação delicada. Em geral, professores sabem mais sobre os assuntos que ensinam do que os utilizam; não usam seu conhecimento como deveriam (saber operacional). Comportam-se, portanto, de modo produtivo quando se trata do saber declarativo, mas o mesmo, muitas vezes, não se aplica ao saber operacional. Professores que ensinam técnicas de administração não são necessariamente bons administradores. Da mesma forma, professores que ensinam seus alunos como ensinar outros alunos podem não colocar em prática aquilo que ensinam (algumas das razões para isso vão muito além da simples capacidade capacitação - do professor, e merecem uma reflexão própria e extensa, fugindo ao escopo deste trabalho).

Skinner (1972), ao falar sobre o manejo de contingências em sala de aula, inicia seu texto assim: 
Por que estudantes vão à escola? Por que eles se comportam em sala de aula? Por que eles estudam e aprendem e se lembram? Essas são perguntas importantes, mas raramente são feitas - possivelmente porque não estamos orgulhosos das respostas. (p. 225)

As indagações de Skinner (1972) reforçam ainda mais a necessidade de estarmos atentos às nossas práticas educacionais, planejando-as sistematicamente. $\mathrm{O}$ fato de muitas vezes nos esquecermos das razões pelas quais estamos ensinando, ou ainda, das razões que fazem com que nossos alunos frequentem nossas aulas, podem indicar que as respostas a essas perguntas não são fáceis de encarar. Muitas vezes lançamos mão do que a Análise do Comportamento chama de controle aversivo. Práticas educacionais antigas enxergavam no castigo corporal a forma ideal de suprimir condutas inadequadas dos alunos, conforme o dito popular: "o pai (ou professor) que poupa a vara odeia o filho (o aluno)".

Com o passar do tempo, o controle aversivo em sala de aula ganhou contornos mais suaves, sendo substituído hoje em dia por tarefas adicionais contingentes a mau comportamento, interações pouco amistosas, críticas constantes, avaliações surpresa, ameaças e cobranças etc. (Skinner, 1991; Zanotto, 2000). A desinformação quanto aos efeitos do controle aversivo, assim como o efeito imediato desse tipo de controle na supressão do comportamento, talvez explique parte do seu uso exagerado. Professores punem demais e elogiam de menos! Utilizam muito mais contingências punitivas e reforçamento negativo do que reforçamento positivo para conduzir suas aulas ao longo dos semestres. As consequências desse comportamento - dos professores - se traduzem em colas, rendimento mediano dos alunos, procrastinação, faltas no limite da frequência exigida pela instituição de ensino, falta de interesse dos alunos, entre outros "efeitos colaterais".

As instituições de ensino buscam avidamente por professores que ministrem aulas espetaculares, que prendam a atenção do aluno, bem como buscam por bons alunos, por meio de processos seletivos com alto grau de exigência. Entretanto, Skinner (1972), ao falar sobre tecnologia do ensino, fez uma interessante consideração sobre a busca por "bons professores" e "bons alunos":

O Mito ou Falácia do Bom Professor é a crença de que o que um bom professor pode fazer, qualquer professor pode fazer ... A Falácia complementar do Bom Estudante é a crença de que o que um bom estudante pode aprender, qualquer estudante pode aprender. ... Nós estamos procurando por bons professores ou por bons alunos ou por ambos, mas não por práticas que foram analisadas e podem ser comunicadas. Nós não podemos melhorar significativamente a Educação encontrando melhores professores e melhores alunos. Nós precisamos encontrar práticas que permitam a todos os professores ensinar bem e a todos os alunos aprender tão eficientemente quantos seus talentos permitirem. (p. 210, grifo nosso).

A atualidade das palavras de Skinner (1972) é surpreendente. A procura por bons professores e bons alunos é bastante evidente nas instituições de ensino; já a procura por práticas de ensino eficazes, que estejam desvinculadas de características específicas de alunos e professores, é mais rara. O PSI é uma dessas práticas de ensino.

\section{O Plano de Keller e a Universidade de Brasília}

A criação do PSI apresenta uma estreita relação com o Brasil, especificamente com a Universidade de Brasília (Keller, 1968, 1972; Todorov, 1996; Todorov, Nazzaro \& Nazzaro, 1972). Uma história mais completa sobre a criação de ambos pode ser apreciada alhures (Todorov, 1996, 2003). Transcreveremos aqui apenas alguns trechos de Todorov (2003) para que o leitor possa perceber o estreito vínculo entre o PSI e a Universidade de Brasília:

Fred S. Keller veio ao Brasil em 1961 como um Fulbright Scholar para ensinar durante um ano como professor visitante na Universidade de São Paulo ... O sucesso de seu trabalho levou ao convite de um segundo Fulbright Scholar, John Gilmour (Gil) Sherman, na época um jovem Ph.D. da Universidade de Columbia. Gil Sherman, Keller, Carolina Martuscelli Bori e Rodolpho Azzi, convidados pela Universidade de Brasilia, planejaram e começaram a implantar o curso de psicologia da UnB, incluindo o desenvolvimento e a aplicação do Sistema Personalizado de Ensino (PSI).... Em março de 1963, os planos para um departamento de psicologia em Brasília foram discutidos com Keller em Nova Iorque. Ele parecia entusiasmado com a idéia: "Decidi me juntar a eles quando terminasse minhas obrigações com Columbia. Continuei a ensinar da maneira tradicional por mais um semestre. Entretanto, foi muito dificil pensar em qualquer coisa exceto Brasília e nossas operações futuras a serem desenvolvidas lá." ... A Introdução à Análise Experimental do Comportamento foi planejada como uma disciplina de dois semestres. O primeiro semestre era basicamente o curso como originalmente planejado por Fred Keller e W. N. Schoenfeld na Universidade de Columbia, usando o K\&S como texto. O curso foi adaptado para um sistema personalizado de ensino por Keller e Gil Sherman e testado naquela universidade em 1963. O PSI foi, a seguir, completamente desenvolvido para a Universidade de Brasília pelo esforço de oito colaboradores, incluindo Carolina Martuscelli Bori e Rodolpho Azzi e começou em agosto de 1964. ( p. 341)

O PSI - ou Plano de Keller como também ficou conhecido - produziu resultados extraordinários (Keller, 1968; Kulik, 1976; Fox, 2004; Todorov, 1996, 2003), tornando-se bastante popular na década de 70 (ver Nale, 1998, para uma revisão de trabalhos sobre programação de ensino no Brasil e as contribuições de Carolina Martuscelli Bori). Após a desativação do Centro de Instrução Personalizada de Georgetown, verificou-se um decréscimo dramático - não se sabe exatamente quanto tempo após - no número de cursos baseados no PSI, bem como no número de publicações sobre o programa (Fox, 2004). Várias foram as razões para o declínio do PSI, mas, como apontou Fox (2004), a despeito de que fatores tenham contribuído para o declínio do PSI, ineficiência em melhorar a aprendizagem e o desempenho dos alunos não foi um deles. 
O PSI pode ser sumariamente descrito apresentando-se suas diferenças em relação ao ensino tradicional. São cinco suas características principais: domínio sequencial do conteúdo; ênfase na palavra escrita; ritmo próprio; papel indispensável do tutor; e aulas e demonstrações como veículo de motivação (Fox, 2004; Moreira, 2004; Keller, 1968).

Domínio sequencial de conteúdo. O conteúdo da disciplina é cuidadosamente dividido em pequenas unidades e o aluno só avança de uma unidade para outra após demonstrar domínio da unidade anterior. A avaliação da aprendizagem de cada unidade (sequencial de cada conteúdo) pode assumir formas diversas como, por exemplo, perguntas de múltipla escolha, questões de completar, respostas dissertativas curtas, demonstração prática de alguma habilidade e testes orais.

$\mathrm{Na}$ maioria dos cursos em que o PSI foi utilizado entendeu-se domínio do conteúdo como $100 \%$ de acerto nas avaliações, sejam elas formadas por questões fechadas, dissertativas, escritas, orais ou práticas. Isso é possível porque os conteúdos abordados são pequenos e cada aluno pode refazer uma avaliação quantas vezes forem necessárias para demonstrar domínio daquele conteúdo. Além disso, esse critério diminui as chances do aluno ter dificuldades de aprender um novo conteúdo por falhas na aprendizagem de conteúdos anteriores relacionados.

Ênfase na palavra escrita. Geralmente, em cursos tradicionais, boa parte das informações críticas para o aluno poder aprender são passadas oralmente pelo professor (e.g., instruções sobre o quê e como estudar; explicações e exemplos adicionais). Se uma informação é importante, o aluno deve poder acessá-la quando for necessário. Em um curso PSI, todas as informações necessárias para que o aluno possa dar seguimento aos seus estudos são passadas a ele de forma escrita. Com o avanço da informática e da internet, essa característica do PSI ganhou novos contornos (e.g., conteúdos multimídia) e maior versatilidade em relação às formas de acesso à informação (Fox, 2004; Koen, 2002; Martin, Pear \& Martin 2002; Pear \& Crone-Todd, 1999).

Ritmo próprio. Em um curso PSI cada aluno pode conduzir seus estudos em seu próprio ritmo. Como a programação do curso não é baseada em um calendário acadêmico, nem em aulas expositivas, e cada aluno recebe seu próprio material, ele pode conduzir seus estudos independentemente do ritmo de seus colegas. Se um aluno não atinge os critérios necessários para passar para uma nova unidade, ele pode revisar o conteúdo e tentar novamente. Isto não impede outros alunos que atingiram o critério de aprendizagem de uma unidade de avançar em seu curso. Contudo, alguns trabalhos (e.g., Fox, 2004; Koen, 2001) apontam que essa característica do curso deve ter uma atenção especial, no sentido de especificar contingências para reduzir a procrastinação dos alunos no decorrer do curso.

O papel indispensável do tutor. Essa é uma característica essencial do PSI. Durante o curso, sempre que o aluno necessitar, ele pode contar com a ajuda de um tutor (geralmente um outro aluno que finalizou o mesmo curso). O tutor, além de prover feedback imediato para os alunos, sobretudo nos momentos de avaliação das unidades, fomenta os aspectos sociais do processo ensino-aprendizagem.
Quando o aluno recebe feedback logo após ter concluído um exercício ou feito uma pergunta, os efeitos do feedback sobre a aprendizagem do aluno são muito mais poderosos. Em salas de aula com 40 ou 50 alunos é praticamente impossível para o professor fornecer feedbacks apropriados a todos os seus alunos. Com o auxílio de tutores, cada aluno pode ter atenção individual sempre que necessitar, tornando-se assim possível dispor consequências adequadas e no momento certo para as necessidades de cada aluno, quando e como eles precisarem.

Aulas e demonstrações como veículo de motivação. No PSI, aulas expositivas e demonstrações têm papel motivacional, em vez de fonte crítica de informações para o transcorrer da disciplina. Cada aluno recebe seu próprio material (manuais, resumos, texto, listas de exercícios etc) e é instruído sobre como conduzir seus estudos, também de forma escrita, não havendo necessidade de aulas para transmissão do conhecimento. Obviamente, sempre que o aluno não conseguir extrair do material escrito as informações e conhecimentos necessários, ele pode - e deve - recorrer ao professor ou um dos tutores para auxiliá-lo.

É comum, no PSI, que o aluno participe de uma aula (cuja presença não é obrigatória) apenas após dominar o conteúdo que será tratado naquela aula. Essa característica, em revisões mais recentes do método (e.g., Fox, 2004; Koen, 2002), tem sido apontada como secundária. Uma característica importante dessas aulas expositivas é produzir no aluno o interesse pelo tema da disciplina. Entretanto, essas aulas não apresentam um caráter repetitivo, mas sim, demonstram ao aluno a abrangência do tema em questão, aprofundando ou extrapolando o escopo da disciplina. Vale ressaltar também que não é durante essas aulas que o aluno irá esclarecer suas dúvidas em relação à matéria. Como foi dito anteriormente, as dúvidas deverão ser sanadas nos outros horários previamente disponibilizados para esse fim.

A ideia principal implícita nessa característica é a de fornecer consequências reforçadoras ao comportamento dos alunos que dominaram o conteúdo da matéria, o que é necessário para participar dessa aula motivacional. Essas aulas podem constituir-se, por exemplo, em demonstrações experimentais e aulas dadas fora do ambiente institucional (e.g., visitas a museus, bibliotecas, centros urbanos históricos e universidades).

Para Skinner (1968), o aprendizado formal significa arranjar contingências de reforçamento de forma a levar as pessoas a se comportarem; significa estabelecer condições para o surgimento do comportamento desejado e consequências que possam fazer com que esse comportamento possa reaparecer novamente nas mesmas condições. Nesse sentido, o professor deve estar ciente dos objetivos que quer alcançar, ou seja, deve estabelecer claramente os comportamentos que ele deseja observar no repertório de seus alunos. Estabelecer condições para que o comportamento ocorra significa preparar o aluno com leituras prévias necessárias, esclarecer suas dúvidas, fornecer feedback adequado para os mínimos avanços do aluno, evitar (ou minimizar) o contato do aluno com o fracasso e a frustração etc. Tudo isso é mais fácil de fazer em uma relação direta entre professor/tutor e aluno do que em salas de aula lotadas. 


\section{Ensino à Distância}

O desenvolvimento de tecnologias de transmissão de informação vem garantindo um espectro enorme de possibilidades de comunicação entre pessoas distantes, tanto espacialmente quanto temporalmente. $O$ processo educacional, logicamente, teria que incorporar essas tecnologias com vistas a ampliar o número de pessoas instruídas por algum método formal de educação, assim como levar o conteúdo de diferentes áreas do conhecimento a regiões que não oferecem condições mínimas para um ensino presencial. A Internet tem propiciado grande elasticidade ao EAD ao permitir que a informação seja trocada de forma extremamente eficiente e veloz, superando barreiras geográficas e oferecendo alternativas ao sistema de ensino presencial (Dahmer, 2006). Caracterizado pelo distanciamento físico entre professor e aluno, o EAD, segundo Moore e Kearsley (1996), pode ser dividido em três etapas quanto ao seu desenvolvimento: estudo por correspondência; cursos por intermédio de televisão, rádio e telefone; e EAD baseado em redes de computadores. De acordo com Dahmer (2006), não ocorreu a substituição de uma alternativa pela outra, mesmo em tempos de pleno desenvolvimento de tecnologias que permitem que a informação seja rapidamente enviada de um lugar a outro. As novas alternativas foram sendo incorporadas, ajustando-se às anteriores e criando novos modelos. Ainda hoje, cursos à distância são conduzidos por correspondência.

A EAD possui uma ampla gama de definições (e.g., Holmberg, 1981; Peters, 2003; Preti, 1996). De forma geral, as definições para EAD tomam, como ponto de partida, o ensino convencional em sala de aula. O que há de comum entre todas elas é a distância, compreendida enquanto espaço. A separação entre professores e alunos não está clara em algumas definições, mas constitui-se em fator determinante no processo de ensino e aprendizagem à distância.

Para Aretio (2001), existem alguns elementos fundamentais para a caracterização da EAD: (1) separação alunoprofessor - professor e aluno encontram-se separados no espaço e, na maioria das vezes, no tempo; (2) organização de apoio-tutoria - a tutoria propicia acompanhamento do curso e das dificuldades encontradas pelo aluno; (3) aprendizagem independente e flexível - a tecnologia permite o trabalho independente do aluno e a individualização da aprendizagem; (4) comunicação bidirecional - feedback entre educador e aluno; (5) enfoque tecnológico - educação otimizada pela utilização da tecnologia e de um planejamento sistemático; e (6) comunicação massiva - a transmissão/recepção de mensagens é facilitada pelas novas tecnologias de informação e pelos modernos meios de comunicação, possibilitando o aproveitamento dessas mensagens por um grande número de pessoas dispersas espacialmente.

\section{PSI e EAD: Aprendizagem Centrada no Aluno}

Ao retirar do professor e transferir ao aluno o papel de ator principal no ensino, tanto o PSI quanto a EAD rompem com os paradigmas educacionais tradicionais nos quais o professor como transmissor de conhecimento é o aspecto crítico.
A adaptação de uma determinada disciplina para o PSI ou para a EAD exige uma reformulação cuidadosa do material que será disponibilizado para o aluno. Muitas das funções exercidas pelo professor dentro de sala de aula como, por exemplo, exposição oral do conteúdo, instruções de como, do que e quando estudar, explanações sobre os tópicos abordados, entre outras, são substituídas, pelo menos em um primeiro momento do processo de ensino-aprendizagem, por resumos explicativos, recursos audiovisuais, textos auxiliares, roteiros de estudo, pequenos testes que podem ser feitos e corrigidos várias vezes, dentre outros inúmeros recursos, que dependerão dos objetivos de cada disciplina. Essa re-elaboração do material didático, além de melhorar sua qualidade, ainda permite que todas as informações críticas para a aprendizagem do aluno estejam à sua mão nos momentos em que lhe for necessário ou conveniente.

O desenvolvimento tecnológico, notadamente o advento da Internet, aproximou ainda mais essas duas formas de se ensinar. Com o uso das Novas Tecnologias da Informação e da Comunicação, o material utilizado pelo aluno, em um curso no formato PSI, além de ganhar muito em qualidade, fica acessível on-line para o aluno. As atividades de tutoria podem ser exercidas via chat ou fóruns de discussão assíncrona pela Internet. A verificação do domínio de cada conteúdo pode ser também realizada on-line. Enfim, todas as características essenciais do PSI não só podem ser implantadas em um curso à distância, bem como podem ser otimizadas, sobretudo no que se refere ao registro e acompanhamento das atividades dos alunos.

\section{Aproximações Graduais do PSI à EAD}

Embora o uso da informática e da internet não seja uma condição sine qua non para a implementação de cursos à distância ou cursos baseados no PSI, tais tecnologias têm sido utilizadas amplamente em ambas modalidades de ensino. Utilizar os recursos da Internet em um curso nos moldes do PSI parece ser um passo razoavelmente simples que permite a transformação quase que automática de um curso presencial em um curso à distância. $\mathrm{O}$ uso da Internet em cursos baseados no PSI, entretanto, foi precedido pelo uso da informática (softwares locais), o que parece ter sido uma estratégia interessante, pois essa fase pode ter funcionado como uma fase de transição, permitindo o aprimoramento e a adequação dos recursos utilizados.

Crosbie e Kelly (1993), por exemplo, em função da baixa disponibilidade de tutores em sua instituição de ensino, utilizaram softwares e microcomputadores para realizar parte do trabalho dos tutores em um curso nos moldes do PSI. Para conduzir o curso, com 51 alunos de graduação recém ingressados na instituição de ensino, foram necessários um professor, um aluno de graduação e 20 microcomputadores instalados em um laboratório (geralmente cursos PSI utilizam um tutor para cada 10 alunos). Os textos utilizados na disciplina foram digitalizados e um programa computacional específico foi elaborado para a aplicação de testes. Cada aluno possuía um disquete com uma chave de acesso ao programa de testes. Cada teste poderia ser realizado quantas vezes fos- 
sem necessárias para que o aluno apresentasse domínio do conteúdo. Os testes eram baseados em um banco de questões e cada teste realizado apresentava questões diferentes sobre os conteúdos avaliados. Além de apresentar os escores nos testes, o programa computacional apresentava feedback imediato para cada questão respondida e registrava no próprio disquete do aluno seu histórico em relação aos testes.

Crosbie e Kelly (1993) afirmam que seu curso foi um sucesso tanto em termos de aprendizagem dos alunos quanto em termos de sua satisfação: os alunos relataram não sentirem falta de mais tutores ou mais tempo com o tutor do curso. $\mathrm{O}$ uso de computadores e softwares em cursos nos moldes do PSI tem recebido o nome de Computer-Aided Personalized System of Instruction (CAPSI). Pear e Crone-Todd (1999) estenderam o uso dos recursos da informática em um curso CAPSI permitindo o acesso ao conteúdo (textos, instruções, telefones e e-mails dos tutores etc.) e aos testes através de uma rede local (acesso de qualquer computador do campus). Além disso, os alunos que possuíam hardwares (e.g., modem) e softwares específicos (e.g., pcANYWHEREC) poderiam acessar o conteúdo da disciplina e os testes de computadores fora do campus.

Uma característica interessante do curso CAPSI conduzido por Pear e Crone-Todd (1999) reside no fato de que os testes das unidades eram compostos por questões abertas. O software utilizado para gerenciar os testes armazenava as respostas dos alunos e designava automaticamente um tutor para a correção das mesmas. Os alunos, geralmente, recebiam o feedback sobre sua avaliação em um período de 24 horas. Pear e Crone-Todd relataram que a maioria dos alunos completou todas as unidades do curso e $80 \%$ procrastinaram em pelo menos uma unidade.

Um exemplo direto da "transformação" de um curso PSI em um curso EAD, com uso da world wide web, é apresentado por Koen (2001). Koen elaborou um curso introdutório de programação de computadores em PSI para calouros de engenharia. Todo o curso foi realizado via web. No meio do semestre, por razões profissionais, o professor, que residia nos Estados Unidos, teve que viajar para o Japão, de onde continuou ministrando o curso sem qualquer prejuízo para o andamento ou qualidade deste.

\section{O PSI como Paradigma Básico para a Educação à Distância}

Coldeway e Spencer (1982), ao discutirem algumas das características do PSI, sugeriram o uso deste como o paradigma básico para a Educação à Distância, apresentando vantagens e desvantagens de tal uso. Algumas das vantagens apresentadas por eles são:

A abordagem do PSI especifica uma relação clara entre o desenho do curso e a forma de disponibilizá-lo. ... O PSI funciona como um guia para o desenho do curso (pois) requer o desenho e o desenvolvimento dos componentes-chave da instrução. Em geral, esses componentes incluem objetivos, instruções para os estudantes, material com o conteúdo, ... múltiplas formas de avaliação .... O PSI coloca cada aprendiz em um papel ativo e responsável ... O PSI provê o registro contínuo e atualizado do desempenho e do não-desempenho dos aprendizes ... O PSI é flexivel ao longo de suas dimensões ..., pode ser usado com uma grande quantidade de domínios de conteúdo e instituições ... Quando corretamente implementado, o PSI provê uma importante fonte de múltiplos dados para o uso em revisões e alterações do curso ... $\boldsymbol{O}$ PSI não compete com outras teorias de desenvolvimento instrucional, mas provê uma estrutura na qual elas podem ser examinadas ... (pp. 61-65, grifo nosso)

Algumas das características do PSI, destacadas por Coldeway e Spencer (1982) como vantagens do PSI como um paradigma básico para a educação à distância, talvez não devessem ser descritas como "vantagens do PSI", mas sim como características necessárias a qualquer tipo de atividade de ensino. Por exemplo, a descrição precisa dos objetivos e de como alcançá-los, instruções claras e objetivas, cuidado na escolha e elaboração do material didático, avaliação variada e continuada, ênfase em um papel ativo do aluno, feedback apropriado e registro constante do desempenho dos alunos para reavaliação da atividade de ensino, deveriam ser características de qualquer curso ou disciplina (obviamente, devemos lembrar que o professor precisa ter condições apropriadas para desenvolver um curso com essas características, o que parece não ser a regra em nosso sistema de ensino).

Outro ponto importante, ou vantagem, destacado por Coldeway e Spencer (1982) refere-se ao fato do PSI não necessariamente competir com outras metodologias ou estratégias de ensino. O PSI é uma metodologia de ensino baseada nos pressupostos da Análise do Comportamento, mas, por exemplo, um professor de orientação cognitivista poderia sem muitos problemas utilizar tal metodologia, incorporando a ela princípios e atividades baseados na taxonomia de Bloom (1956), como o fizeram Crone-Todd e Pear (2001) em um curso CAPSI.

Coldeway e Spencer (1982) também apresentam e discutem algumas das desvantagens de se adotar o PSI como paradigma básico para a educação à distância. Algumas delas são:

O PSI requer uma razoável quantidade de flexibilidade (ritmo próprio) ... se uma quantidade razoável de flexibilidade não é uma opção, essa restrição pode ser uma desvantagem do PSI como paradigma para a educação à distância. ... O PSI requer sistemas de avaliação criativos e inteligentes quando questões de múltipla-escolha e respostas-curtas não funcionarão. ... todos os envolvidos no desenho e aplicação do curso terão que aceitar as doutrinas básicas do domínio do conteúdo ... O PSI requer um cuidadoso sistema de registro dos desempenhos dos alunos ... (pp. 66-69)

A possibilidade do aluno imprimir seu próprio ritmo de aprendizagem ao curso é uma característica fundamental do PSI. Essa característica, entretanto, não representa uma dificuldade de implementação, como apontado por Coldeway e Spencer (1982), apenas para cursos à distância. As instituições de ensino, incluindo seus sistemas computacionais, estão preparadas para semestres letivos que têm data de início e fim. Permitir ao aluno que avance em seu próprio ritmo parece ser mais uma decisão administrativa que pedagógica. De 
fato, como apontam Grant e Spencer (2003), muitos alunos procuram cursos de EAD em função de sua flexibilidade, sobretudo em relação à administração do próprio tempo para se dedicar aos estudos.

A dificuldade de se criar avaliações consistentes com os objetivos da disciplina também não parece ser uma dificuldade apenas relacionada a cursos à distância. A questão aqui parece envolver mais uma distinção entre uso da informática para prover feedback versus o uso de tutores e assistentes para realizar tal tarefa. Já o domínio do conteúdo (requerer $100 \%$ de acerto em um teste, por exemplo), entretanto, é uma característica do PSI da qual não se pode abrir mão, conforme apontado por Fox (2004), em função dos impactos negativos na aprendizagem dos alunos.

Por fim, uma última desvantagem apontada por Coldeway e Spencer (1982) de se adotar o PSI como paradigma básico para a educação à distância aparece, estranhamente, também como vantagem: registro contínuo do desempenho dos alunos. Mas, como esses autores destacam, essa, entre outras, parece ser mais uma dificuldade do que uma desvantagem propriamente dita. Os recursos da informática disponíveis atualmente tornam essa tarefa relativamente simples e barata.

Coldeway e Spencer (1982) concluem que as vantagens de se adotar o PSI como paradigma básico para a educação à distância sobrepõem-se às desvantagens - entretanto não descartam outras possibilidades, embora não as apresentem. A estreita relação entre PSI e EAD também é sugerida por Grant e Spencer (2003), sendo que estes destacam a ênfase na palavra escrita (impressa ou virtual), e o cuidado na preparação do material didático, sobretudo das instruções, como características essenciais a esta relação.

\section{Considerações Finais}

No capítulo 2 de Ciência e Comportamento Humano, Skinner (1953) faz uma distinção entre o conhecimento científico e outras formas de conhecimento como a Arte e a Filosofia. Ao discutir essas formas de conhecimento, Skinner observa que um cientista hoje tem muito mais domínio sobre a natureza do que um cientista há 400 anos. Um artista hoje não é, entretanto, necessariamente mais eficiente que um artista (um pintor, por exemplo) 400 anos atrás. A explicação para tal fato seria a de que o conhecimento científico é cumulativo, apóia-se sobre o anterior; cada nova geração de cientistas começa seus trabalhos apoiada no solo firme do conhecimento produzido por aqueles que os precederam. Ser um bom professor parece ainda ser uma arte. Como foi apontado no início do texto, o professor de hoje - ou a educação de hoje não é, necessariamente, mais eficaz que o professor (ou a educação) de ontem. Ainda insistimos em ensinar da forma como fomos ensinados.

Skinner (1991) afirma que "os educadores voltaram sua atenção para a descoberta e a criatividade, num esforço de interessar seus estudantes, mas boas contingências de reforço fazem isso de uma forma muito mais aproveitável” (p. 142). Para que tais contingências possam ser estabelecidas, é necessário que olhemos para a educação de uma forma mais pragmática, buscando metodologias que explicitem práticas de ensino efetivas e, até o ponto em que for possível, "importar" dos laboratórios o rigor experimental que caracteriza a produção de conhecimento científico, que tanto já contribui para a melhoria da qualidade de vida dos seres humanos. Devemos deixar um pouco de lado o "Mito do Bom Professor" e o "Mito do Bom Aluno" e procurar por práticas de ensino que possam ser compreendidas e ensinadas.

Algumas dessas práticas de ensino podem ser encontradas em um livro que foi lançado recentemente nos Estados Unidos intitulado Evidence-Based Educational Methods, organizado por Daniel J. Moran e Richard Malott (2004). Essa obra apresenta quatro metodologias de ensino que possuem vasta evidência empírica de sua eficiência, a saber: Direct Instruction; Precision Teaching; Computerized Teaching; e Personalized System of Instruction. A eleição do PSI, mesmo quatro décadas depois de sua criação, para compor essa obra ressalta a robustez dos dados produzidos nos milhares de cursos em que foi utilizado nos seus 40 anos de existência. Cabe ressaltar que o objetivo da obra supracitada não é apresentar algumas metodologias de ensino que são eficazes em detrimento de outras, mas sim apresentar métodos de ensino que tiveram sua eficácia comprovada de acordo com o rigor da ciência.

Em Evidence-Based Educational Methods, Eric Fox (2004) faz uma apresentação do PSI de rara clareza e riqueza de informações, discutindo questões relativas à sua história - ascensão e declínio. Fox também faz uma reflexão sobre a implementação do PSI no século XXI, ressaltando a junção entre PSI e o uso de novas tecnologias de informação e comunicação. Nessa reflexão torna-se clara a estreita relação entre Sistema Personalizado de Ensino e Educação à Distância, mesmo não tendo sido apontada diretamente pelo autor. Unir PSI e EAD pode ser uma alternativa viável para a disseminação e democratização de um ensino de qualidade, alicerçado em evidências empíricas de sua eficácia. Por fim, acreditamos, baseados no que foi exposto neste trabalho, que olhar para essas duas metodologias de ensino pode ser, no mínimo, uma fonte de inspiração para a construção de qualquer prática de ensino, presencial ou não.

\section{Referências}

Aretio, L. G. (2001). La educación a distancia: De la teoria a la práctica. Barcelona: Ariel Educación.

Baum W. M. (1999). Compreendendo o behaviorismo: ciência, comportamento e cultura (M. T. A. Silva, organizadora da tradução). Porto Alegre: Artmed. (Trabalho original publicado em 1994)

Bloom, B. S. (1956). Taxonomy of educational objectives: Cognitive and affective domains. New York: David McKay.

Catania, A. C. (1999). Aprendizagem: comportamento, linguagem e cognição (D. G. Souza., organizadora da tradução). Porto Alegre: Artes Médicas. (Trabalho original publicado em 1989)

Coldeway, D. O., \& Spencer, R. E. (1982). Keller's Personalized System of Instruction: The search for a basic distance learning paradigm. Distance Education, 3, 51-71.

Crone-Todd, D. E., \& Pear, J. J. (2001). Application of Bloom's taxonomy to PSI. Behavior Analyst Today, 3, 204-210. 
Crosbie, J., \& Kelly, G. (1993). A computer-based personalized system of instruction course in applied behavior analysis. Behavior Research, Methods, Instruments, and Computers, 25, 366-370.

Dahmer, A. (2006). Um modelo para processo de curso. Tese de Doutorado, Universidade Federal do Rio Grande do Sul, Porto Alegre.

Fox, E. J. (2004). The personalized system of instruction: A flexible and effective approach to mastery learning. Em D. J., Moran \& R. W. Malott (Eds.), Evidence-based educational methods: Advances from the behavioral sciences (pp. 201-221). San Diego: Elsevier Academic Press.

Grant, L. K., \& Spencer, R. E. (2003). The Personalized System of Instruction: Review and applications to distance education. International Review of Research in Open and Distance Learning, 4, 1-17. Retirado em 16/03/09, de http://www.irrodl.org/index.php/ irrodl/article/view/152/705

Holmberg, B. (1981). Educación a distancia: Situación y perspectivas. Buenos Aires: Editorial Kapelusz.

Keller, F. S. (1968). “Good-bye teacher ...” Journal of Applied Behavior Analysis, 1, 79-89.

Keller, F. S. (1972). Adeus mestre... Ciência e Cultura, 24, 207-217.

Koen, B. V. (2001). Contingencies of reinforcement to maintain student progress throughout a web-based PSI course. Retirado em 16/03/09, de http:/www.eecs.kumamoto-u.ac.jp/ITHET01/ proc/037.pdf.

Koen, B. V. (2002). Web-based implementation of the Personalized System of Instruction (PSI) in a mechanical engineering required freshman computer course. Retirado em 16/03/2009, de http://files.asme.org/asmeorg/Governance/Honors/1100.pdf.

Kulik, J. A. (1976). PSI: A formative evaluation. Em B. A. Green, Jr., (Ed.), Personalized instruction in higher education: Proceedings of the second national conference (pp. 140-145). Washington, DC: Center for Personalized Instruction.

Marrou, H. (1966). História da Educação na Antiguidade. São Paulo: Herder.

Martin, T. L., Pear, J. J., \& Martin, G. L. (2002). A computeraided personalized system of instruction course. Journal of Applied Behavior Analysis, 35, 427-430.

Moore, M., \& Kearsley, G. (1996). Distance Education: A system view. Belmont: Wadsworth Publishing.

Moran, D. J. (2004). The need for evidence-based educational methods. Em D. J. Moran \& R. W. Malott (Eds.), Evidence-based educational methods: Advances from the behavioral sciences (pp. 3-7). San Diego: Elsevier Academic Press.

Moran, D. J., \& Malott, R. (Eds.). (2004). Evidence-based educational methods: Advances from the behavioral sciences. San Diego: Elsevier Academic Press.
Moreira, M. B. (2004). "Em casa de ferreiro, espeto de pau": o ensino de Análise Experimental do Comportamento. Revista Brasileira de Terapia Comportamental e Cognitiva, 6, 73-80.

Nale, N. (1998). Programação de ensino no Brasil: o papel de Carolina Bori. Psicologia USP, 9, 275-301.

Pear, J. J., \& Crone-Todd, D. E. (1999). Personalized system of instruction in cyberspace. Journal of Applied Behavior Analysis, 32, 205-209.

Peters, O. (2003). A educação à distância em transição. São Leopoldo: Unisinos.

Preti, O. (1996). Educação à distância: indícios de um percurso. Cuiabá: NEAD/IE - UFMT.

Ryle, G. (1949). The concept of mind. London: Hutchinson.

Skinner, B. F. (1953). Science and human behavior. New York: McMillan.

Skinner, B. F. (1968). The technology of teaching. New York: Appleton-Century Crofts.

Skinner, B. F. (1972). Cumulative Record (3 ${ }^{\mathrm{a}}$ ed.). New York: Appleton-Century-Crofts.

Skinner, B. F. (1991). Questões recentes na análise comportamental (A. L. Néri, Trad.). São Paulo: Papirus. (Trabalho original publicado em 1989)

Todorov, J. C. (1996). Goodbye teacher, good old friend. Journal of the Experimental Analysis of Behavior, 66, 7-9.

Todorov, J. C. (2003). Science and human behavior translated into portuguese: Ciência e Comportamento Humano. Journal of the Experimental Analysis of Behavior, 80, 341-343.

Todorov, J. C., Nazzaro, J. R., \& Nazzaro, J. N. (1972). Student ability and individualized instruction. Journal of College Science Teaching, 2, 29-30.

Todorov, J, C., \& Tristão, G. (1975). Sistema personalizado de ensino: bases psicológicas e abordagem administrativa. Cadernos de Psicologia Aplicada, 3, 65-71.

Zanotto, M. L. B. (2000). Formação de professores: a contribuição da Análise do Comportamento. São Paulo: Educ. 